\title{
The Moral Authority of Teacher in Preparing Students for Patriotic Education
}

\author{
Nikolai V. Kuzmin \\ Mari State University, Yoshkar-Ola, Russia \\ Email: djacore@list.ru
}

Doi:10.5901/mjss.2015.v6n3s7p11

\section{Abstract}

Future teachers' consciousness of morality or immorality of moral standards, formation of belief in need of the approval of socio-historical rules of human community has to be completed at student's age. The teacher has to be focused on humanity, improvement of society, on versatile development of the personality, and for this purpose, he has to be the integral personality, the carrier and the spokesman of humanistic values. Respectively the high school teacher on whom depends formation of the identity of future teacher has to be the spokesman and the carrier of humanistic values also. The task of the teacher consists in assistance to the student at development of a subjective scale of values. This article is devoted to a role of moral authority of the teacher in training of students of pedagogical specialties of higher educational institutions of professional education for implementation of patriotic education of the younger generation. The main result of article is the developed complex of pedagogical abilities, which are a basis of the pedagogical activity allowing solving problems of patriotic education Materials of article can be useful to teachers of schools, teachers of professional education and for students of pedagogical specialties of higher teacher training institutions.

Keywords: moral authority, teachers, patriotism, civil, students, patriotic education

\section{Introduction}

The social and economic, political and sociocultural changes occurring in the country the last 15-20 years left a mark on public consciousness, led to negative consequences among youth, in particular:

- to revaluation of values of the previous generations;

- to destruction of intergenerational communications;

- $\quad$ to violation of continuity in transfer of sociocultural experience. (Lutovinov, 1999).

Researches of these years (N. I. Danilin, I.A. Galitskoy, V.A. Karakovsky, A.I. Kravchenko, I.V. Metlik, A.V. Mudrika, L.A. Popova, N. I. Kuznetsova, V. S. Sobkin, V. Terekhov, etc.) testify to valuable crisis in the youth environment. In this regard, the question of a key role of modern values and traditions becomes actual.

When the former system of values is rejected and new only arises, valuable reference points of teachers, which have impact on formation of moral and valuable orientations of youth, play an important role in education of youth. (Kuzmin \& Galliulin, 2010).

The personality, being guided by social values, chooses close ones to his soul as standards of behavior and forms his subjective scale of values, or the valuable orientations defining the individual relation to social values. The choice is defined by:

a) views and representations;

b) orientation to this or that system of values;

c) possibility of achievement, realization.

Set of values by which future teacher is guided can be regarded as an expert assessment of his social and moral maturity. We can speak about future teacher as personality judging by the values, coinciding with what human society recognizes among the most significant or not.

However the students - the most plastic part of society, also are under the influence of social changes, a foreign policy situation, economic life of society, activity of mass media, etc. In the course of formation of the personality occurs not only assimilation of norms, which have historical character, but also moral standards, and rules of a public conduct of concrete society.

Future teachers' consciousness of morality or immorality of moral standards, formation of belief in need of the approval of socio-historical rules of human community has to be completed at student's age. The teacher has to be focused on humanity, improvement of society, on versatile development of the personality, and for this purpose, he has to 
be the integral personality, the carrier and the spokesman of humanistic values. Respectively the high school teacher on whom depends formation of the identity of future teacher has to be the spokesman and the carrier of humanistic values also. (Shaidullina, et al. 2015).

The task of the teacher consists in assistance of the student at development of a subjective scale of values. Problematical character of the solution of this task consists in absence of ready rules, accurately certain modern scale of values, need of independent decisions and responsibility for them.

The important factor defining transfer and acceptance of values is process of social comparison of:

- values of the fatherland with universal values and values of other states;

- domestic values of different stages of historical development;

- achievements of the Russian society with other states and provisions it within the world community;

- real situation in society depending on policy of the state.

Comparison causes approval of values, their recognition and defines aspiration to their statement and realization. (Johnston, 2007).

The table of humanistic values of the teacher is made.

Based on the analysis of philosophical and historical literature, religious sources, scientific and pedagogical researches, conversations with teachers and teachers of higher education institutions of the Republic of Mari El, comparison of different scales of values of teachers and students, the table can serve as the model defining education of humanistic values at future teachers.

Table 1. Humanistic Values of Teacher
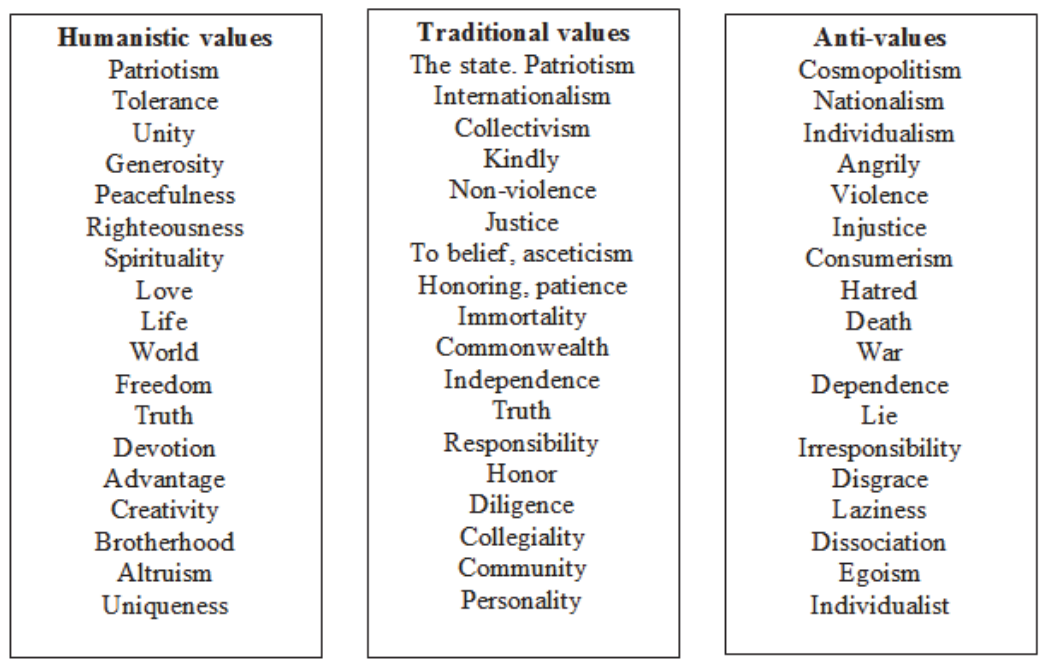

In the right column there are "anti-values" which are not peculiar in general to the Russian society are located. In average - traditional values to which the Russian pre-revolutionary society, socialist society and which remain in modern Russian society. Some terms accepted the generalized character. (For example, a collectivism - a solidarity of purpose and interests of the governor and the people, etc. Internationalism - unity of the nations and nationalities in the Russian state, socialist internationalism in the Soviet state, the multicultural relations within the Russian Federation, etc.)

In the left column, there are humanistic values, which can define formation of the humanistic relations. According to this model, it is important to seek for disclosure of uniqueness of each personality and formation of the highest requirements in future teachers.

\section{Material and Methods}

During research, empirical and theoretical methods were used. Universal methods of empirical research were applied: polls, questioning, interviewing, testing, and expert assessment.

Theoretical methods: analysis of literature, modeling, philosophical, sociological, politological methods of research. The main theoretical methods were the ones of the analysis and synthesis, induction and deduction, analogies and comparison, the system and structural analysis. 


\section{Results and Discussion}

These days the Russian society needs the teacher-citizen, the convinced patriot who is characterized by: morality, kindness and at the same time insistence, sincere generosity, sincere service to the Fatherland, humanity.

In the conditions of the keeping break in the spiritual sphere and culture, in the conditions of a value crisis it is very important that today In Russia each teacher act as a bright example of patriotic service to the Homeland and the humanistic relation to the world. It has always been the prime vital target of Great Russian teachers. K.D. Ushinsky noted that no charters and programs could replace the identity of the teacher in education. P.F. Kapterev considered one of important factors of success of pedagogical activity "personal qualities" of the teacher. (Kapterev, 2014).

In world pedagogics the model of the ideal teacher is actively developed. So, the Japanese teacher Tomomuchi Kiuchi included in this model essential, in his opinion, signs and qualities: ability at the same time to learn and bring up, strong theoretical pedagogical education, high culture, understanding of values of education, freedom, responsibility, participation in intellectual elite.

According to V.A. Slastenin, the modern teacher has to possess:

- abilities of organizational and educational work,

- $\quad$ high culture,

- good knowledge of a foreign language,

- ability independently to get information,

- high moral qualities.

The general list of qualities makes a portrait of the ideal teacher. Its core are personal qualities. There is hardly such an area of human activity but pedagogical, where qualities of the worker so strongly would affect results of work. (Slastenin, Isaev, \& Shiyanov, 2002).

Activity of the teacher depends on a set of factors. It is possible to present this dependence as a structure. Work of the teacher demands from him not only profound and versatile knowledge, the high general culture which is expressed to a professional and pedagogical orientation, moral qualities, though it is the base which defines work of the teacher. It demands also a strong ideological commitment, which is formed in the course of social activity. High level of public activity in many respects depends on a level of development of civil qualities and patriotism of the teacher.

Deep understanding of the social role, the social duty in education of the younger generation creates favorable conditions for all-round development and formation of the most important lines of the identity of the teacher: commitment, organization, persistence, insistence, responsibility. These qualities help the teacher to show strong-willed efforts for achievement of the object in the solution of educational tasks set by him. (Kuzmin, et. al 2015).

Effectiveness of patriotic education substantially is defined by a personal example of the teacher, his highly moral behavior. Many famous Soviet teachers spoke about a crucial role of a personal example of the teacher, his moral shape in education of youth: S. S. Makarenko, V.A. Sukhomlinsky and others. D. A. Belukhin, A.V. Zosimovsky, L.M. Mitina pointed to the importance of a personal example of the teacher. About a role of the high school teacher M. Zinovkina, V. Ivanov, L. Gurye, M. Dobruskin wrote.

The analysis of practical activities of teachers of schools of Joshkar-Ola, Kozmodemyansk, Volzhsk also shows that its efficiency depends on personal qualities of the teacher.

The reasons of moral influence of the identity of the teacher on formation of the identity of the trainee, his patriotism lie in the nature of the relations developing in the course of pedagogical activity. An important reserve of increase of efficiency of educational work in patriotic education is the moral authority of the teacher.

A.S. Makarenko wrote, "without authority the tutor is impossible". The authoritative teacher acts for pupils as the carrier of socially significant norms. Enjoying moral authority, he promotes formation of moral at trainees. The moral authority of the teacher is directly connected with his moral qualities: patriotism and civic consciousness; intelligence and exclusive diligence; adherence to principles and tactfulness; honesty and justice; simplicity and modesty; high insistence to itself and the benevolent attitude towards people. Moral adherence to principles of the teacher grants the right of presentation of moral requirements to pupils and results in productivity in educational activities for development of patriotism, patriotic feelings and moral behavior. (Makarenko, 1968).

Patriotism, civic stand of the teacher actively influence formation of belief of youth. The teacher having own opinion on acute public issues, in relation to history, and not putting pressure categoricity of the statements, always makes world outlook impact on pupils, and spiritualized by idea of the best arrangement of public life promotes replacement of social apathy and uncertainty in tomorrow at youth.

In the conditions of the Perestroika during the Soviet era the answer to a question:

"What qualities are professionally significant for the modern "ideal" teacher?" the following seven were allocated: 
professional knowledge and general erudition, empathy, dominance, commitment and strong-willed qualities, ideological orientation, communicativeness and expression.

In the Soviet society, such quality as "an ideological orientation" was defined by concepts: conviction in advantage of the work, political literacy, communistic outlook, moral purity. If entrants put this quality on the 4th place, students and teachers with an experience from 10 to 20 years - on the 5th. Teachers with an experience from 5 to 10 years - on the 6 th, the teacher with an experience from 0 to 5 years - on the 7th place. (Hand, 2011).

A bit different picture appears today (242 persons took part in poll). Seven qualities were pointed out: professional knowledge and erudition, communicativeness, civic consciousness, dominance, moral purity, expression, empathy. Quality "civic consciousness" included concepts: civic stand, patriotism, ideological conviction, understanding of the social importance of teacher's work. If the former entrants (at the beginning of training in higher education institution) did put this quality on the 7th place, students put it on the 5th, the teacher with an experience from 0 to 5 years and from 5 to 10 years - on the 6th, the teacher with an experience from 10 to 20 years - on the 4th.

It allows seeing an essential difference in a position of entrants as the evidence of patriotic education studying at school. If in Soviet period, the considerable attention was paid to patriotic education, now - much less. (Lutovinov, Melnichenko, 2004).

On the other hand, we see relative stability in a position of students. It is manifestation of independence of thinking rather than result of patriotic education in higher education institution. Irrespective of change of a political situation in the country, the social position of students is rather stable.

For teachers with an experience up to 5 years we observe in both cases decrease in ranks in the corresponding indicators. It is both the result of professional adaptation connected with difficulties of pedagogical work for the former student and an indicator of the relation of this category of teachers to the social security.

It is characteristic for teachers with an experience from 5 to 10 years to show an identical civic stand though their approaches differ a little. This fact can offer the following explanation. Teachers of the 80s of the last century rated highly: professional knowledge and erudition, empathy (responsiveness, keenness, a psychological insight, ability to understand the pupil), dominance (ability to direct, operate others, to lead) and an ability to speak beautifully, emotionality, artistry.

Modern teachers with the same experience rate highly professional knowledge and erudition, communicativeness (openness, sociability, ability to find a common language), empathy and moral purity (honesty, justice, humanity, unselfishness). In our opinion, it is an indicator of a humanization of teaching and educational process when more attention is drawn to the subject-subject relations at school, and an indicator of need of development of spirituality for our country. (Krylov, et. al (2015).

It is characteristic for teachers with an experience from 10 to 20 years today as "civic consciousness" put such quality slightly above, than their predecessors. It can be explained, first of all, with views of teachers which compare public life, a position of the state in relation to social problems at different stages of development. They consider that the level of civil education, has to be much higher, and a position of the state in this question - more accurate and directed on education of citizens of Russia. In this case, they represent a position of the teacher, as spokesman of interests of the state. It was traditional approach in requirements to the teacher during the Soviet period; it also was approved in a position of this group of teachers, as a rule, remained faithful to the teacher's debt. In our opinion, it is also manifestation of civic consciousness and patriotism of teachers: irrespective of a socio-political condition of society to do the main business - to bring up citizens, true patriots of the Fatherland.

The moral authority remains if the teacher systematically is engaged in self-education, self-development. The essence of moral self-education consists in development of moral consciousness, in aspiration to improvement according to a moral ideal. The moral authority depends also on degree of competence, professionalism. The general erudition, profound knowledge educational a subject is, certainly, important components of professionalism. Moreover, the teacher has to know well and a current state of science, its communication with other sciences, with life, with practice. He has also to be able to present the knowledge and to use various means for development of informative and public activity of pupils. Therefore, technique is of no less importance. To conduct teaching and educational activity in the future, the student needs to develop pedagogical abilities. (Semenov, 2008).

It is important to systematize those qualities of the identity of the teacher, which are backbone for definition of the teacher-patriot, teacher-citizen capable to fulfill the teacher's duty, ready to patriotic education of youth.

We can divide into the following groups the qualities of the identity of the teacher capable to effective patriotic education:

1) ethic and pedagogical qualities: high moral and spiritual culture, intelligence, pedagogical step, ability to emotional influence, experience of the responsibility for destiny of future citizen of Russia, need for the creative solution of problems of patriotic education; 
2) ideological and political qualities; protection of interests of the fatherland; conviction in need of formation in Russia of civil society; understanding of a political situation in the world, need of constructive interaction, conviction for need of settlement of the conflicts by peaceful means;

3) moral and psychological qualities: good breeding of patriotic feelings (love to the Fatherland, native places, participation in the world); consciousness of a civic duty; collectivism, mutual aid, tolerance, responsibility; internal self-discipline and self-control; emotional and strong-willed stability; commitment.

4) professional knowledge and abilities necessary for the solution of problems of patriotic education of school students:

knowledge: essence, principles and maintenance of patriotism; purpose and problems of patriotic education; modern directions and regularities of development of patriotism; stories of the fatherland, its role in a preservation of peace and development of world culture; opportunities of the maintenance of the subject, modern achievements of pedagogics, a technique in the creative solution of problems of patriotic education;

abilities:

- the analytic-gnostic: to study the identity of the school student, to determine the level of its patriotism and patriotic consciousness, to predict behavior in difficult life situations;

- the constructive: to plan process of patriotic education, to allocate its stages, the purposes and means of their achievement, to project the course of teaching and educational process in unity with a complex out of educational affairs of a patriotic orientation;

- the organizing: to motivate patriotic activity, to stimulate activity development; to provide pedagogical instrumentation of patriotic actions, to carry out coordination of activity with public organizations;

- the communicative: to consider psychological features of pupils at inclusion in patriotic activity, to achieve unity of student's collective on the basis of patriotic activity;

- the executive and creative: to participate in patriotic affairs and creatively to solve the teaching and educational problems connected with patriotic education.

These abilities in one system can be formulated as "readiness" of future teacher for education of patriotism at youth in educational actions and educational activity.

Thus, it is necessary to refer the moral qualities of the teacher to the humanistic values defining his moral authority. In a complex with pedagogical abilities, they are a basis of the pedagogical activity allowing solving problems of patriotic education. (Kuzmin \& Fathulin, 2011).

\section{Conclusion}

Authority of the teacher-tutor is this major means of educational influence. Authority of the teacher is the special professional position defining influence on students, granting the right to make the decision to express an assessment, to give advice. The original authority of the teacher-tutor is guided not by official and age privileges but on high personal and professional qualities: democratic style of cooperation with pupils, ability to open communication, his aspiration to continuous improvement, erudition, competence, justice and kindness, the general culture, etc. The true authority is attitude of pupils towards the teacher, which induces pupils to be younger companions to the teacher all the time.

Existence of moral authority of the teacher who is defining in the solution of problems of patriotic education. It is connected with the fact that in professional activity of the teacher, the problem of effective formation of moral qualities is prior, what causes importance of his moral authority in teaching and educational process. This aspect of pedagogical activity cannot be ignored. If moral qualities of the teacher are estimated by the trainee as unacceptable, the effective solution of problems of patriotic education is impossible. (Andriadi, 1997).

\section{References}

Andriadi, I. P. (1997). The authority of the teacher and the process of its formation. Moscow, MPGU, 205p.

Johnston, S. (2007). The truth about patriotism. Duke University Press.

Hand, M. (2011). Should we promote patriotism in schools? Political Studies, 59 (2), 328-347.

Kapterev, P.F. (2014). The history of Russian pedagogy. Directmedia.

Krylov, D.A., Kuzmin, N.V., Korotkov S.G., (2015). The Model of Formation of Project Culture of the Future Pedagogue in the Course of Vocational Training. Review of European Studies, Vol. 7, No. 8, p.23-28 DOI: 10.5539/res.v7n8p28

Kuzmin, N.V., Fathulin, B.E. (2011). Problems of military-patriotic education of youth. (p.152). Moscow.

Kuzmin, N.V., Galliulin, D.K. (2010). Modern technology education. (p.332). Moscow.

Kuzmin, N.V., Kuzmin, V.K., Krylov, D.A., Toktarova V.I. (2015). Ideological aspect of training future teachers for patriotic education of 
the youth. Review of European Studies, Vol. 7, No. 8, p.214-221 DOl: 10.5539/res.v7n8p214

Lutovinov, V. I. (1999). In the patriotism of youth - the future of Russia. (p.208) Moscow.

Lutovinov, V. I., Melnichenko, I.I. (2004). Development of patriotism in Russia of the 21st century. (p.256) Moscow.

Makarenko, A. (1968). Educating citizens. Education.

Romashova, S.N. Andriadi, I.P. (2010). Theory Training. Moscow, Academia, 339p.

Semenov, G. S. (2008). Programme of Civic and Patriotic Education of Children and Young People. (p.64). Moscow

Shaidullina, A. R., Maksimova, O. G., Fadeeva, E. Y., Khairullina, E. R., Valeyeva, N. S., Zaripov, R. N., ... \& Kuzmin, N. V. (2015). Development Dynamics Study of Professional and Pedagogical Culture of Communication in Professional Activities of Teachers. Mediterranean Journal of Social Sciences, 6 (2 S3), 216. DOl: 10.5901/mjss.2015.v6n2s3p216,

Slastenin, V. A., Isaev, E. F., \& Shiyanov, E. N. (2002). Pedagogics. Studies. grant for the student. Vyssh. Ped. Studies. Institutions / Century. 